\title{
Pulmonary dysfunction in children with beta thalassemia major in relation with iron overload - a cross sectional hospital based study
}

\author{
A Boddu', A Kumble², S Mahalingam³ ${ }^{3}$ B S Baliga ${ }^{4}$, B Achappa ${ }^{5}$ \\ ${ }^{1}$ Post graduate, Department of Paediatrics, Kasturba Medical College, Mangalore (affiliated to Manipal University), ${ }^{2}$ Professor, Department of \\ Paediatrics, Kasturba Medical College, Mangalore (Affiliated to Manipal University), ${ }^{3}$ Associate Professor, Department of Paediatrics, Kasturba \\ Medical College, Mangalore (affiliated to Manipal University), ${ }^{4}$ Professor \& Head, Department of Paediatrics, Kasturba Medical College, \\ Mangalore (affiliated to Manipal University), ${ }^{5}$ Associate Professor, Department of Internal Medicine, Kasturba Medical College, Mangalore \\ (affiliated to Manipal University) Institute to which the work is affiliated to: Department of Paediatrics, Kasturba Medical College, Mangalore \\ (Affiliated to Manipal University)
}

\section{A B S T R A C T}

Background: Previously many patients with thalassemia major died from severe anemia during first decade, but with modern transfusion therapy many now survive beyond childhood. Because of such therapy, however excessive iron deposition occurs in lungs and causing respiratory dysfunction. Respiratory impairment occurs because of defective chelation and repeated transfusions. Objectives: To a) study pattern of respiratory impairment using spirometry, b) estimate iron overload by measuring serum ferritin levels, c) correlate a\&b. Methodology:Thalassemia children >7year, on regular blood transfusion were included in the study after getting institutional ethical clearance. Standardised pulmonary function test was done using spirometry. Iron overload was assessed using serum ferritin levels. Severity of pulmonary dysfunction was correlated with serum ferritin levels. Results:Total of 42 children were included $62 \%$ were males and $38 \%$ were females (with median age $12 y r s$ ). By spirometry $95 \%$ had restrictive pattern of respiratory dysfunction. Mean ferritin value was 4152 . Out of them 10 (23.8\%) mild, 25(59\%) moderate and $5(12 \%)$ severe dysfunction based on FEV1 and FVC. The mean ferritin values in severe respiratory dysfunction is 6275 which is significantly higher when compared to moderate (4249) and mild (3066) pattern of respiratory dysfunction. None of the children had evidence of CCF. Significant correlation ( $p$ value $=0.003$ ) was found between severity of pulmonary dysfunction with ferritin values and also with weight of the child ( $p$ value $=0.007$ ). No other significant correlation found between severity pattern and transfusion index, age or height. Conclusion:Restrictive pattern is most common pulmonary dysfunction seen in chronic iron overloaded thalassemia major children. Regular blood transfusions with adequate chelation decrease incidence of pulmonary dysfunction. Screening of all thalassemia children using spirometry is need of the hour.

Key words: Thalassemia major, pulmonary function tests, Restrictive pattern, Serum Ferritin
http://nepjol.info/index.php/AJMS DOI: $10.3126 /$ ajms.v6i5.11782

\section{INTRODUCTION}

The Thalassemia is a heterogenous group of heritable hypochromic anaemia of various degrees of severity. Underlying genetic defects include total or partial deletions of globin chain genes and nucleotide substitutions, deletions or insertions. The consequences of these various changes are a decrease or absence of mRNA for one or more of the globin chains or the formation of functionally defective mRNA. The result is a decrease or total suppression of hemoglobin polypeptide chain synthesis. ${ }^{1}$

Clinical manifestations are those of severe anaemia and albeit defective erythropoiesis complicated by lack of affinity

Address for Correspondence:

Dr. Soundarya Mahalingam, Associate Professor, Department of Paediatrics, Kasturba Medical College, Mangalore (affiliated to Manipal University) 
of circulating hemoglobin $\mathrm{F}$ to 2-3 diphosphoglycerate. In other forms of anemia 2-3 diphosphoglycerate constitutes a major compensatory mechanism for oxygen delivery to tissues. As a result of these defects, repeated transfusions are needed to maintain life. Coupled with increased gastrointestinal absorption of iron, this lifelong transfusion requirement causes hemosiderosis.

Children with Beta -thalassemia appear well at birth but develop anemia that becomes progressively worse. If left untreated, this can result in early deaths. Patients with beta -Thalassemia major need regular transfusions in order to live. These children typically, have to receive blood transfusions at least once a month depending on the severity of illness. The resulting iron overload also requires chelation therapy.

Every unit of erythrocytes that is transfused contains 200 to $250 \mathrm{mg}$ of iron as a component of the red heme pigment. As the normal daily loss of iron in sweat and in shed cutaneous and mucosal epithelial cells is only $1 \mathrm{mg}$, a single unit of erythrocytes correspond to about 200 daily rations of iron. Because excess iron cannot be eliminated from the body, it necessarily follows that chronic transfusion therapy brings the body's iron balance very far out of equilibrium. ${ }^{2}$

In order to prevent these toxic effects of iron overload, chelation therapy is being used. Chelation therapy is generally recommended after twenty units of packed cell transfusion or if serum ferritin exceeds 1000 micro gram per deciliter. Therapy with this chelating agent that form complexes with iron and promotes its excretion can clear plasma non transferring bound iron, remove excess iron from cells and return body iron to safe levels. ${ }^{2}$

Various methods of assessing iron overload were by estimating Serum ferritin levels, by measuring Heart function (LVEF), Cardiac MRI, and also measuring hepatic iron concentration by invasive methods like Liver biopsy and non-invasive like MRI liver.

This study was undertaken to study the respiratory impairment in $\beta$-thalassemia patients on regular $(>20)$ transfusions in relation to iron overload. Objectives of this study were to a)To study the pattern of respiratory impairment using spirometry. b)To estimate iron overload with serum ferritin levels and with these values correlation of the respiratory impairment with iron overload in Thalassemia patients.

\section{MATERIALS AND METHODS}

A total of 42 cases of thalassemia were included in the studyafter getting clearance from institutional ethical committee. Informed consent was obtained from either of the parents of the children selected upon satisfying both inclusion and exclusion criteria and a semi structured proforma was prepared to record all data. They were instructed to abstain from any other medications (apart from chelators) $24 \mathrm{hrs}$ before transfusion. Just before transfusion venous sample collected from all participants and serum ferritin levels were assessed, then participants were subjected for pulmonary function tests using standardised spirometry.Children advised to take few normal respirations followed by deep inspiration then momentary breath holding and advised for forced \&fast expiration as hard\& as long as possible for 6sec. Same procedure was repeated for 3 times and the best effort was taken.

Based on spirometry measurements the respiratory impairment pattern (obstructive or restrictive) was described and correlated with serum ferritin levels. The pulmonary deficits were classified ${ }^{8}$ as "mild" (>70\%), "moderate" $(<70 \%$ and $>60 \%)$, "moderately severe" $(<60 \%$ and $>50 \%)$, and "severe" $(<50 \%)$.

All diagnosed children with thalassemia between 6-15 yrs of age on regular transfusions ( $>20$ transfusions) and on chelation therapy were included, other than thalassemia children who were already diagnosed cases of pulmonary dysfunction (i.e. asthma, pneumonia, tuberculosis, bronchiectasis and chronic lung disease) and recurrent cases of pneumonia (>3episodes/yr).

\section{RESULTS AND ANALYSIS}

A total of 42 children included in study majority (61.9\%) were males, and $47.6 \%$ were in between $11-14$ yrs of age.As per IAP and ICMR charts majority of children were underweight and stunted for age with 85.7 and $95.2 \%$ respectively (Table 1 ). All children were on regular

\begin{tabular}{lcc} 
Table 1: Demographic details & \\
\hline \multicolumn{1}{l}{ Frequency } & Percent \\
\hline A) Gender & 26 & \\
Male & 16 & 61.9 \\
Female & & 38.1 \\
B) Age (in years) & 15 & \\
$7-10$ & 20 & 35.7 \\
$11-14$ & 7 & 47.6 \\
15 and above & 42 & 16.7 \\
Total & & 100 \\
C) Weight for age & 36 & 85.7 \\
Underweight for age & 6 & 14.3 \\
$\quad$ Normal & & \\
D) Height for age & 40 & 95.2 \\
$\quad$ Stunted & 2 & 4.8 \\
$\quad$ Normal & 42 & 100 \\
$\quad$ Total &
\end{tabular}


transfusions with majority of them requiring more than $150 \mathrm{ml} / \mathrm{kg} / \mathrm{yr}(62 \%)$.

Out of 42 children in study group $95 \%$ were having restrictive type of respiratory dysfunction. Majority $(59.5 \%)$ of the children in the study had moderate dysfunction followed by mild $(23.8 \%)$ and severe $(11.9 \%)$ respectively (Table 3). The mean ferritin values in severe respiratory dysfunction is 6275 which is significantly higher when compared to moderate (4249) and mild (3066) pattern of respiratory dysfunction (Table 4). Most of the children with severe respiratory dysfunction are significantly associated with high serum ferritin levels ( $p$ value 0.003 ).

Collected data was analysed using SPSS version 16.0 for both qualitative and quantitative data. For statistical analysis Spearman's Correlation Coefficient, ANOVA P test and paired $t$ tests were used wherever applicable. $P$ value of $<0.05$ was considered significant.

\section{DISCUSSION}

Beta thalassemia children on regular transfusions and inadequately chelated are at a risk for iron overload. Like in

\begin{tabular}{|c|c|c|c|}
\hline & Mean & Std deviation & Median \\
\hline Age & 11.98 & 2.513 & 12.00 \\
\hline Weight (kg) & 28.40 & 6.121 & 28.00 \\
\hline Height $(\mathrm{cm})$ & 129.62 & 9.178 & 130.00 \\
\hline Ferritin & 4152.57 & 1882.776 & 3739.00 \\
\hline FEV1 & 64.66 & 14.849 & 62.80 \\
\hline FVC & 65.233 & 12.2485 & 62.550 \\
\hline FEV1/FVC & 96.912 & 8.5963 & 97.900 \\
\hline
\end{tabular}

\begin{tabular}{lccc} 
Table 3: Distribution of lung function \\
\hline Severity type & Obstructive & Restrictive & Percentage \\
\hline Mild & 0 & 10 & 23.8 \\
Moderate & 0 & 25 & 59.5 \\
Severe & 0 & 5 & 11.9 \\
Total & 0 & 40 & 95 \\
\hline $5 \%$
\end{tabular}

$5 \%$ were having normal lung function

\begin{tabular}{|c|c|c|c|c|c|c|}
\hline \multirow[t]{2}{*}{ Ferritin } & \multirow[t]{2}{*}{$\mathbf{N}$} & \multirow[t]{2}{*}{ Mean } & \multirow[t]{2}{*}{$\begin{array}{c}\text { Std. } \\
\text { deviation }\end{array}$} & \multicolumn{2}{|c|}{$\begin{array}{l}\text { 95\% Confidence } \\
\text { interval for mean }\end{array}$} & \multirow{2}{*}{$\begin{array}{c}\text { ANOVA } \\
\text { F test } \\
P \text { value }\end{array}$} \\
\hline & & & & $\begin{array}{l}\text { Lower } \\
\text { bound }\end{array}$ & $\begin{array}{l}\text { Upper } \\
\text { bound }\end{array}$ & \\
\hline Normal-mild & 12 & 3066.42 & 1393.96 & 2180.73 & 3952.10 & \multirow[t]{4}{*}{0.003} \\
\hline Moderate & 25 & 4249.28 & 1482.92 & 3637.16 & 4861.40 & \\
\hline Severe & 5 & 6275.80 & 2926.41 & 2642.18 & 9909.42 & \\
\hline Total & 42 & 4152.57 & 1882.77 & 3565.86 & 4739.29 & \\
\hline
\end{tabular}

all organs, iron gets deposited in the pulmonary interstitium causing pulmonary hemosiderosis. This results in slowly worsening pulmonary function.

Iron accumulation from repeated transfusions has been proposed as the likely mechanism causing pulmonary defect in thalassemia major patients. Serum ferritin values have been found to have direct correlation to iron deposition in the liver. Serum ferritin is an acute phase protein as well as a product of hepatocellular damage. Thus, infection, congestive heart failure, and hepatitis can lead to a falsely increased measurement. None of patients included in study had clinical evidence of hepatitis or heart failure.

In this study 42 children were included out of which majority of them were males and belonging to11-14yrs. No correlation was found between demographic data like age, sex with pattern of pulmonary dysfunction which is in contrast to study done by $\mathrm{Al} \mathrm{Ali} \mathrm{M} \mathrm{K} \mathrm{et} \mathrm{al} \mathrm{where} \mathrm{they}$ foundstatistical significancebetween age and serum ferritin levels and pattern of respiratory dysfunction.

Anthropometry assessment was also done for all children included in this study and found that majority of them were underweight and stunted for age. A significant correlation was noticed between pulmonary dysfunction and weight for age where as height did not show any significant association which has not been proven in any previous study.

On assessing the pulmonary function with spirometry, the most common abnormality observed in this study, affecting $95 \%$ of patients with thalassemia major was restrictive type of respiratory dysfunction (Table 3). This is similar to other published studies done by Rahim et $\mathrm{al}^{4}$ and Bourli et $\mathrm{l}^{6}$ where restrictive abnormalities were most frequently reported. Studies done by Kanj et $\mathrm{al}^{4}$ and Amin et $\mathrm{al}^{7}$ showed both Obstructive and Restrictive pattern of Respiratory dysfunction.

A study was conducted by Amin et $\mathrm{al}^{7}$ in fifty thalassemia major children who were on regular blood transfusion and also on chelation therapy. Pulmonary function tests were performed in all subjects using spirometry. Thirty-five children $(70 \%)$ had abnormal result of spirometry with restrictive pattern. Obstructive airway disease was detected in 4 patients $(8 \%)$. There was no significant correlation between abnormal pulmonary function test and serum ferritin level in children with thalassemia.

A study done on 59 thalassemia patients by Rahim et $\mathrm{al}^{5}$, where pulmonary function tests and arterial blood gas analyses were performed. All investigations were performed $24 \mathrm{hr}$ before the patients received a blood transfusion or when they were hemodynamically stable. 
Pulmonary function tests however showed a reduction of all main parameters (TLC, $\mathrm{FEV}_{1}, \mathrm{FEV}_{1} / \mathrm{FVC}$ ) indicating a restrictive type of pulmonary dysfunction. Arterial blood gases done were within normal limits. No evidence that the observed abnormalities in pulmonary function were secondary to congestive heart failure. Iron deposition due to repeated blood transfusions may play a central role in determining lung alterations although the majority of patients are well chelated, suggesting that more than one causal mechanism could be involved.

As our study has shown deteriorating lung function with inadequate chelation, improving the compliance to chelation, changing the chelator used where required andregular monitoring of lung function will have significant change in arresting the pulmonary hemosiderosis and the lung dysfunction thereafter.

Some limitations of this study were: a) This study is cross sectional assessment of lung function. b) Smaller sample size is another limitation. c) Ideal quantitative assessment of iron overload is measuring hepatic iron content by liver biopsy which in view of its invasive nature was not feasible and hence not included in this study. d) It would be more informative to follow these patients and assess longitudinal changes of their lung function.

\section{CONCLUSION}

To conclude from this study, the most common abnormality in pulmonary function in chronically transfused beta thalassemia children on chelation is Restrictive type of
Pulmonary Dysfunction. The severity of this pulmonary dysfunction is statistically significantly associated with higher serum ferritin values.

\section{REFERENCES}

1. Michael RD, Eliott V: Chapter 462 Hemoglobinopathies- Nelson textbook of Pediatrics $19^{\text {th }}$ edition, Kliegman Saunders, 2033.

2. Paul A. Marks, Thalassemia syndromes: biochemical, genetic and clinical aspects. N Engl J Med 1966; 275:1363-9

3. Neufeld EJ. Update on iron chelators in thalassemia. Am J Hematol 2010:451-55.

4. Kanj N, Shamseddine A, Gharzeddine W, Kanj M, Nasr TA, Koussa $S$, et al. Relation of ferritin levels to pulmonary function in patients with thalassemia major and the acute effects of transfusion. Eur J Haematol. 2000 Jun; 64(6):396-400.

5. F. Rahim, Keikhaei B and Ebadi, 2008. A clinical manifestation of Pulmonary dysfunction in beta Thalassemia major Journal of medical sciences, 8;484-90.

6. E Bourli, M Dimitriadou, MEconomou, E Vlachaki, AChristoforidis, EMaratou et al. Restrictive pulmonary dysfunction and its predictors in young patients with $\beta$-thalassaemia major. PediatricPulmonol. 2012 Aug; 47(8):801-7.

7. FM Abu-Ekteish, H S Al-Rimawi, M K Al-Ali,I M Shehabi. Pulmonary function tests in children with beta-thalassemia major Chronic Respiratory Disease 2007February, 4: 19-22.

8. Fung KP, Chow OK, So SY, Yuen PM. Pulmonary function in thalassemia major.J Pediatr. 1987 Oct;111(4):534-537.

9. J M Factor, S R Pottipati, I Rappoport, I K Rosner, M L Lesser, and $P$ J Giardina "Pulmonary function abnormalities in thalassemia major and the role of iron overload." American Journal of Respiratory and Critical Care Medicine,1994;149(6)1570-4. doi: 10.1164/ajrccm.149.6.8004315

10. J M Gomori, G Horev, H Tamary, J Zandback, L Kornreich, R Zaizov,et al. Hepatic iron overload: quantitative MR imaging. Radiology 1991 179:2, 367-369. 